\title{
Evaluation of the Use of Skin Homograft for Management of Major Burn Patients
}

\author{
MOHAMED A. MEGAHED, M.D.**; SHERIF M. EL-KASHTY, M.D.**; AHMED T. NASSAR, M.D.** and \\ HEBA R.A. ELKHOULY, M.Sc.*
}

The Department of Plastic and Reconstructive Surgery, Damietta Specialized Hospital, Damietta* and Faculty of Medicine, Menoufia University**, Egypt

\begin{abstract}
Objective: To evaluate the use of skin homograft in major burn patients as regard indications, percentage of taking, cosmetic outcome, cost, and complications. In addition to comparing various laboratory data and notice the incidence of systemic inflammatory response syndrome (SIRS) occurrence pre-and post-operatively. And detect the mortality rate among the patients managed with homograft.

Background: Burn is a type of physical trauma to skin or tissue. It can be produced by heat, chemical products, cold, electricity, or radiation. Burn can lead to loss of skin, resulting in deep, widespread skin wounds or even death. Therefore, finding an appropriate skin substitute in such patients is one of the main concerns of clinicians.

Method: This prospective comparative study was done at the Department of Plastic and Reconstructive Surgery, Menoufia University Hospitals, from December 2017 to July 2020. It was conducted on 31 patients with major burns; to evaluate the use of skin homograft in major burn patients regarding indications, the percentage of taking, the survival time, and the complications. Also, to detect the incidence of occurrence of systemic inflammatory response syndrome (SIRS) and the mortality rate among the patients managed with homograft. All studied patients and donors were subjected to take a full history, general and local examination, investigations as complete blood counts (CBC), blood glucose level, kidney and liver function tests, electrolytes, and coagulation profile. Also, preoperative preparation, intraoperative and postoperative care was done.
\end{abstract}

Results: The present study revealed that there was a highly significant decrease in postoperative temperature, heart rate, respiratory rate, systemic inflammatory response (SIRS) score, total leucocytic count (TLC), and K measurements in homograft patients $(p<0.05$ respectively). Comparative study between pre-and post-operative measurements revealed; a highly significant increase in post-operative albumin and $\mathrm{Na}$ measurements in homograft patients ( $p<0.05$ respectively).

Conclusion: The current work concluded that the use of homograft in major burn patients improved their overall condition by improving laboratory and respiratory data postoperatively. Furthermore, it reduces the raw area, reduces fluid and electrolyte loss, and aids rapid wound healing. Furthermore, we discovered a significant reduction in the SIRS score, which reduces sepsis and improves morbidity and mortality.
Key Words: Burn - Homograft - Systemic Inflammatory Response Syndrome (SIRS).

\section{INTRODUCTION}

Burn is a type of physical trauma to skin or tissue. It can be produced by heat, chemical products, electricity, or radiation. It is one of the most common causes of loss of skin with deep, wide spread skin wounds or even death as a result. So, one of the main concerns of physicians is finding adequate skin substitutes for such patients. Severe burns are those that exceed $15 \%$ in an adult or $10 \%$ in a child [1].

Both the dermis and epidermis of skin are affected in deep burn. The fluid oozes from the burned area, as there is no barrier against fluid loss, resulting in dehydration and electrolyte disturbance. Skin is considered a physical barrier that prevents fluid loss, and a chemical barrier that prevents the growth of bacteria [2]. The splitthickness autologous skin graft is the best choice for burn dressing in full-thickness injuries [3]. Although artificial substances have been tested, none has been more effective than the skin itself in protecting the open wound and controlling bacterial growth. Also, it involves a variable thickness of the dermis and the epidermis, which saves time for healing by secondary epithelization and keratinocytes migration from its edges [4].

Burn patients are already suffering from "systemic inflammatory response syndrome". SIRS described as the pathophysiologic reaction to trauma, infection, pancreatitis, burns, or any other type of injury [5]. As a result, the conversion of an open wound to a closed wound is the most important step in the recovery and early prevention of these complications [6]. 
Because of the limitation of the healthy undamaged skin in extensive burn injuries, there is insufficient autologous skin [7], resulting in a higher mortality rate and longer hospital stay. Allograft or homograft is a tissue or organ from another member of the same species [8]. Human skin allografts have long been used for wound coverage and are one of the most successful and widely used dressings for burn wounds around the world [9]. They can aid in the improvement and preparation of the granulation tissue in the recipient bed. A human skin allograft is integrated into the recipient tissue bed and will be covered by epidermal cells from the recipient [10].

\section{Aim of the work:}

To assess the use of skin homograft in major burn patients as regard indications, percentage of taking, cosmetic outcome, and the complications. In addition to comparing various laboratory data and notice the incidence of SIRS occurrence preand post-operatively. And detect the mortality rate among the patients managed with homograft.

\section{PATIENTS AND METHODS}

The current prospective study was done at the Plastic and Reconstructive Surgery Department, Menoufia University Hospitals, from December 2017 to July 2020. 31 patients were enrolled in the present study, with an age range from ( 8 months to 65 years old). The patients presented with major burns and were managed by homograft, and followup was done for six months.

Patients who are eligible are chosen based on a set of the following criteria:

\section{Inclusion criteria:}

1- Major burn patients with limited donor site availability for autograft.

2- Deep dermal burn patients.

\section{Exclusion criteria:}

1- Superficial burn patients that are suspected to heal conservatively without intervention.

2- Patients with severe inhalation injury or severe medical conditions interfere with the operation.

3- Patients have less than $15 \%$ total burn surface area (TBSA) in adults, or less than $10 \%$ TBSA in children.

4- Patients who refused the operation.

Method:

For the recipients:

All the patients had major burns in varied body areas. Therefore, all of them received their primary survey and resuscitation treatment.
- Full history was taken from all patients.

- General examination including:

1- The general condition of patients and vital signs.

2- Head and neck examination. Inhalation injury was diagnosed by history, presence of facial burn, singed nasal hair, carbonaceous sputum, and laryngeal edema.

3- Chest, abdominal and pelvic examination, upper and lower limbs examination.

- Local examination:

Burn areas are examined carefully to detect:

1- Total burn surface area (TBSA), according to Lund and Browder's chart.

Calculating the total burn area percentage relay only on deep burn (partial-thickness and full thickness burn). So, it is almost $100 \%$ of the total size of the burn that has been mentioned in the current study.

2- The burn wound depth was categorized only into two major groups; either superficial, which was excluded, or deep which was included. Finally, the whole total burn area was excised to be covered with the homograft.

3- Presence of any debris, chemicals, or other foreign bodies within the wound.

4- Signs of infection within the wound (e.g., purulent or malodor discharge, redness, or swelling around the wound).

- Investigations:

Laboratory: $\mathrm{CBC}$ (HB, WBCs, Platelets), ABGs (PH, PCO2, Na, K), albumin, electrolytes, Creatinine, and blood urea to evaluate kidney function, SGPT, SGOT, and prothrombin time to evaluate the hepatic function.

Radiological: Chest X-ray in case of chest infection or inhalation injury suspicion.

Instrumental: Bronchoscopy if inhalation injury was suspected.

The SIRS was detected in patients who managed by homograft pre-and post-op when two or more of the following criteria were met:

- Temp. $>38$ or $<36 \mathrm{c}$.

- RR > 20 breaths/min.

- HR $>90$ beats/min.

- Paco $2<32 \mathrm{mmHg}$.

- WBCs $>12000$ or $<4000$. 
These investigations were done pre-and postoperative to monitor the patient condition continuously, and the investigation parameters were recorded.

\section{For the donors:}

The Source of homograft donors was either first- or second-degree relatives. All the donors signed written consent for donation of their skin, explaining the procedure, its benefits, timing, and complications.

Full personal, present, and past history were taken.

\section{Management:}

A primary survey was performed on all patients once they reached the hospital.

Consequently, the patients went to primary cleansing of the burn wound, and debris was removed, then the burn surface area and depth were determined. The wound was covered with Silver Sulfadiazine and gauze dressing, Then the patients' weight was determined.

After resuscitation and evaluation of the patients' condition, they were categorized according to the percentage of the burn wound, presence or absence of inhalation injury, or presence or absence of other comorbidities. Some were admitted to burn ICU, others to intermediate care, and lastly, some were admitted to the ward.

All studied patients received their primary resuscitation treatment, including:

1- Proper fluid resuscitation: Regarding Evans's formula:

First 24 hours: $2 \mathrm{ml}$. crystalloids x BW x TBSA + Daily fluid requirements (Glucose $5 \%$ ).

Half of this calculated amount was given in the first 8 hours, while the other half was given in the next 16 hours.

Second 24 hours: Half the calculated amount of the previous formula + daily fluid requirements (Glucose 5\%). And Colloid was given according to the patients' needs. The other half of the previous formula was given in the next 24 hours.

2- Broad-spectrum antibiotics to cover grampositive, gram-negative bacteria and anaerobes according to hospital policy (e.g., penicillin and gentamicin).

3- Systemic steroids in the form of dexamethasone IV. are also given to reduce the inflammatory reaction and decrease the pain.
4- Proper analgesic regarding WHO analgesic ladder.

5- Proton pump inhibitors (e.g., Controloc) to avoid stress ulcer occurrence.

6- Other supportive measures are given according to the patient's condition (e.g., packed RBCs, FFP, bronchodilators, inotropes...).

Monitoring of the patients by pulse, BP, central venous pressure (CVP) after insertion of a central line, and urine output (UOP) after insertion of a urinary catheter was also done.

After stabilization, the patients were prepared and underwent primary excision of the burn eschar (escharectomy), then the wound was covered with skin homograft (Figs. 1,2).

The homograft operation was conducted early (within three days) to avoid SIRS, sepsis, and septic shock. In some cases, the operation was postponed, either due to a delay in the patient's arrival to the hospital after burn trauma or unavailable donors.

\section{Donor preparations:}

Pre-operative preparation: Pre-operatively, all donors were evaluated generally and locally before the operation. Anesthesia consultation was carried out along with full laboratory investigations including complete blood count (CBC) (e.g., Hb, WBCs, platelets...), electrolytes, blood grouping, fasting, and postprandial blood sugar, albumin and liver functions tests, kidney functions tests, coagulation profile, virology profile including HIV, hepatitis $\mathrm{B}$, and hepatitis $\mathrm{C}$ viral infections.

Intraoperative preparations and operative procedure:

- Antibiotic prophylaxis: Antibiotics were given before the operation as $1 \mathrm{gm}$ of $3^{\text {rd }}$ generation cephalosporin direct IV route, one hour preoperatively.

- Patient positioning: The donors were placed in a supine position as the preferable donor site for harvesting was the thigh.

- Anesthesia: Anesthesia was either spinal (29 cases) or general (2 cases).

After sterilization of the donor site, splitthickness skin graft harvesting was done using a Humby knife. Coverage with a bulky dressing for the donor site wound was performed. 
Recipient's preparations:

Preoperative preparation:

- Pre-operatively, all recipients were evaluated generally and locally before the operation. An anesthesia consultation was carried out. Along with full laboratory investigations including complete blood count (CBC) (e.g., Hb, WBCs, platelets...), blood grouping, electrolytes, fasting, and postprandial blood sugar, albumin, liver and kidney functions tests, coagulation profile, and virology profile including HIV, hepatitis B, and Hepatitis $C$ viral infections.

- Packed RBCs also was prepared for all recipient patients for the possible need for blood transfusion.

Intraoperative preparations and operative procedure:

- Antibiotic prophylaxis: Antibiotics were given before the operation as $1 \mathrm{gm}$ of $3^{\text {rd }}$ generation cephalosporin direct IV route, one hour preoperatively.

- Patient positioning: The donors were placed in a supine position as the preferable donor site for harvesting was the thigh. While the recipients' position was either supine or prone, depending on the site of the burn.

- Anesthesia: Recipients' anesthesia was general (30 cases), spinal (1 case).

For the recipient, sterilization of the wound was done. Then, tangential excision technique with a Humpy's knife till well bleeding surface was obtained.

The prepared homograft was applied to the recipient patient either immediately or later (kept in the fridge for a maximum of 7 days) according to the burn wound preparation and its liability for taking. Then fixation of the homograft with staples, followed by application of a bulky dressing. Splinting of the joints was usually done with a slap to maintain posture and prevent contracture.

\section{Post-operative care:}

After fixation of the graft and closure of the wound, the patient was transferred to the ward, and a normal diet was allowed after complete recovery. Patient monitoring by regular general and local examination, obtaining vital signs, monitor urine output, laboratory investigations including complete blood count (CBC) (e.g., Hb, WBCs, platelets...), arterial blood gases (ABG), white blood cells (WBCs), albumin, platelets, electrolytes, blood urea, and Creatinine to evaluate the kidney function, SGPT, SGOT, and prothrombin time to assess the hepatic function. These investigations were performed regularly post-operatively up to discharge.

Drugs as antibiotics were given according to the hospital policy, proper analgesics and other supportive therapy were given depending on the patients' condition and needs.

The first dressing on the graft usually was done after 48 to 72 hours. Then the dressing was let open with topical antibiotic spray application.

Rejection was suspected on day 7 to day 14 post-operative as a form of acute rejection, which may last up to one month. Chronic rejection was also suspected in the long run. Any signs of local allergic reaction as erythema, edema, local infection, or partial or total homograft loss were detected and documented for each patient. Suppose there was any sign of considerable graft rejection, infection, or loss. In that case, the patient is kept in the hospital and prepared for another session of homograft (if available) or autograft if possible.

Ethical considerations: All participants were informed about the study's purpose, laboratory, or radiological investigations. Consent was taken from all participants. At the completion of the study, all patients were informed about the results of the examinations performed and received proper recommendations and treatment. The current work has followed The World Health Organization (WHO) and the Declaration of Helsinki recommendations in terms of protecting the well-being and the rights of the studied people [11].

\section{Statistical Methodology:}

Statistical analysis was carried out using MedCalc ver. 18.11.3 (MedCalc, Ostend, Belgium).

The following tests were used:

- $p$-value: Level of significance: $(p>0.05$ : Nonsignificant (NS), $p<0.05$ : Significant (S).

- Mean, Standard deviation ( $\pm \mathrm{SD}$ ) and range for parametric numerical data, while Median and Inter-quartile range (IQR) for non-parametric numerical data.

- Frequency and percentage of non-numerical data.

- Mann-Whitney's Test (U test) was used to assess the statistical significance of the difference of a non-parametric variable between two study groups.

- Repeated measures and factorial ANOVA tests were used to assess the statistical significance of the difference between more than two (paired) study group means. 
- Friedman's test was used to assess the statistical significance of the difference of a nonparametric variable between more than two (paired) study group means.

- Chi-Square test was used to examine the relationship between two qualitative variables.

\section{RESULTS}

The current prospective study was done at the Department of Plastic and Reconstructive Surgery, Menoufia University Hospitals, from December 2017 to July 2020. 31 patients were enrolled in the present study, with an age range from (8 months to 65 years old), suffering major burns, and managed by homograft, with a follow-up period of six months.

Regarding basic demographic and clinical data: The median age of all patients was (5) years with interquartile range (IQR) (2-16). Regarding the gender of the patients, $(54.8 \%)$ of patients were males, while $(45.8 \%)$ were females. $(3.2 \%)$ of patients were smokers and had DM and HCV, respectively. Also, $(6.5 \%)$ of patients had HTN, and (12.9\%) had bronchial asthma (Table 2).

Regarding general burn data, the percentage of burn surface area (TBSA) varied from $10 \%$ to $70 \%$ with a median $(25 \%)$ (Table 3 ), and the median time from the occurrence of burn to homograft application was (6) days. Regarding the cause of the burn, $(6.5 \%)$ of patients had direct contact burn, $(38.7 \%)$ had flame burn, $(54.8 \%)$ had scaled burn (Table 1).

Comparative study between pre- and postoperative measurements revealed a highly significant decrease in post-operative temperature, HR, $\mathrm{RR}$, SIRS score, TLC, and K measurements in homograft patients ( $p<0.05$ respectively) (Tables $4,5)$.

Comparative study between pre- and postoperative measurements revealed a highly significant increase in post-operative albumin and $\mathrm{Na}$ measurements in homograft patients $(p<0.05$ respectively). Comparative study between pre- and post-operative measurements revealed; a nonsignificant difference in post-operative PCO2, Hemoglobin, platelets, creatinine, urea, PT, SGPT, and SGOT measurements in homograft patients ( $p>0.05$ respectively) (Tables 4,5 ).

Regarding blood transfusion, it was in the form of packed RBCs (red blood cells) and FFP (fresh frozen plasma), 9 cases (29\%) needed blood transfusion pre-operatively, 12 cases $(38.7 \%)$ needed blood transfusion pre-and post-operatively, 2 cases (6.5\%) needed blood transfusion post-operatively, and 8 cases $(25.8 \%)$ did not need a blood transfusion.

Regarding post-operative outcome data, the median rejection \% was (50\%), and the median length of hospital stay (LOS) was (21) days. Regarding the final decision, $(81.5 \%)$ of patients had conservative therapy, $(18.5 \%)$ had a small area of autograft. The mortality rate was $(12.9 \%)$, and $(32.3 \%)$ suffered from wound infection (Table 6).

\section{The fate of homograft was either:}

1- Complete take of the homograft with no rejection ( 2 cases) (Figs. 3 ).

2- Partial or complete rejection with healing by wound sealing and fibrosis (20 cases) (Figs. $4,5)$.

3- Partial or complete rejection with a small raw area or dermal pad requires another thin layer of split-thickness autograft (5 cases).

4- Wound infection which managed by the proper antibiotic (after culture and sensitivity) according to the hospital policy with appropriate wound dressing (6 cases).

5 - Deterioration of the general condition of the patient and death (4 cases).

And regarding the donors, there were no complications or comorbidities that have been reported.

Table (1): Cause of the burn in this study.

\begin{tabular}{ll}
\hline Variables & Frequency $(\%)$ \\
\hline Cause of burn: & \\
Direct contact & $2(6.5 \%)$ \\
Flame & $12(38.7 \%)$ \\
Scaled & $17(54.8 \%)$ \\
\hline
\end{tabular}

Table (2): Comorbidities and smoking among the study patients.

\begin{tabular}{lc}
\hline Variables & Frequency $(\%)$ \\
\hline Smoking & $1(3.2 \%)$ \\
HTN & $2(6.5 \%)$ \\
DM & $1(3.2 \%)$ \\
Bronchial asthma & $4(12.9 \%)$ \\
HCV & $1(3.2 \%)$ \\
\hline
\end{tabular}

HTN: Hypertension. DM: Diabetes mellitus. HCV: Hepatitis C.

Table (3): Total burn surface area among the study patients.

\begin{tabular}{ll}
\hline Burn surface area & Median (IQR) \\
\hline TBSA $(\%)$ & $25(16-38.7)$ \\
PT $(\%)$ & $7(0-10)$ \\
FT $(\%)$ & $20(10-35)$ \\
\hline
\end{tabular}

TBSA: Total burn surface area. FT : Full-thickness burn.

PT : Patrial-thickness burn. IQR: Interquartile range. 
Table (4): Laboratory assessments of the patients. The results were recorded the day just before the operation, post-operative day 3 (POD3), post-operative day 7 (POD7), and the day of discharge.

\begin{tabular}{|c|c|c|c|c|c|}
\hline Variables & $\begin{array}{l}\text { Pre-operative } \\
\text { Measurement } \\
\text { Median (IQR) }\end{array}$ & $\begin{array}{c}\text { POD3 } \\
\text { Measurement } \\
\text { Median (IQR) }\end{array}$ & $\begin{array}{c}\text { POD7 } \\
\text { Measurement } \\
\text { Median (IQR) }\end{array}$ & $\begin{array}{c}\text { Discharge } \\
\text { Measurement } \\
\text { Median (IQR) }\end{array}$ & $\begin{array}{l}\text { Friedman's } \\
\text { test } \\
p \text {-value }\end{array}$ \\
\hline $\mathrm{Hb}(\mathrm{g} / \mathrm{dL})$ & $10(9.4-11.2)$ & $10.9(9.9-11.8)$ & $10.8(9.5-12.3)$ & $11.5(10.2-12.7)$ & $>0.05$ \\
\hline $\operatorname{PLT}\left(10^{3} / \mu \mathrm{L}\right)$ & $283(180-395)$ & $301(203-369)$ & $302(200-446)$ & $335(161-376)$ & $>0.05$ \\
\hline Creat. (mg/dL) & $0.5(0.4-0.6)$ & $0.5(0.3-0.6)$ & $0.5(0.3-0.7)$ & $0.5(0.4-0.6)$ & $>0.05$ \\
\hline Urea (mg/dL) & $13.5(9-17)$ & $13.5(10-16.5)$ & $13.5(10.5-20.5)$ & $11(8-18)$ & $>0.05$ \\
\hline PT (sec) & $15.4(13.9-17.5)$ & $14.1(12.9-15.4)$ & $14(13.6-14.6)$ & $13.6(12.5-14.9)$ & $>0.05$ \\
\hline SGPT (U/L) & $17(14.2-29.2)$ & $21(17.7-29)$ & $33(16.2-45)$ & $21(18-56.7)$ & $>0.05$ \\
\hline SGOT (U/L) & $33(27-41)$ & $33.5(20-41)$ & $38.5(25-40)$ & $39.5(25-49)$ & $>0.05$ \\
\hline Alb. (g/dL) & $2.6(2.1-2.9)$ & $2.7(2.4-3.3)$ & $3.3(3-3.6)$ & $3.5(2.9-3.8)$ & $<0.05$ \\
\hline $\mathrm{Na}(\mathrm{mEq} / \mathrm{L})$ & $133(131-136)$ & $138(137-142)$ & $138(135-142)$ & $139(136-145)$ & $<0.05$ \\
\hline $\mathrm{K}(\mathrm{mEq} / \mathrm{L})$ & $4.3(4.1-4.7)$ & $4(3.7-4.9)$ & $4.1(3.8-4.5)$ & $3.9(3.6-4.3)$ & $<0.05$ \\
\hline $\begin{array}{l}\mathrm{Hb}: \text { Hemoglo } \\
\text { PLT : Platelets. } \\
\text { TLC : Total leu } \\
\text { SGPT : Alanine t } \\
\text { SGOT : Aspartate }\end{array}$ & $\begin{array}{l}\text { count. } \\
\text { inase. } \\
\text { minase. }\end{array}$ & $\begin{array}{l}\text { Alb : Albumin. } \\
\text { Creat. : Creatinine. } \\
\text { PT : Prothrombin time. } \\
\text { IQR : Interquartile range. }\end{array}$ & & & \\
\hline
\end{tabular}

Table (5): SIRS parameters among the studied patients. The results were recorded the day just before the operation, postoperative day 3 (POD3), post-operative day 7 (POD7), and the day of discharge.

\begin{tabular}{|c|c|c|c|c|c|}
\hline Variables & $\begin{array}{l}\text { Pre-operative } \\
\text { Measurement } \\
\text { Median (IQR) }\end{array}$ & $\begin{array}{c}\text { POD3 } \\
\text { Measurement } \\
\text { Median (IQR) }\end{array}$ & $\begin{array}{c}\text { POD7 } \\
\text { Measurement } \\
\text { Median (IQR) }\end{array}$ & $\begin{array}{c}\text { Discharge } \\
\text { Measurement } \\
\text { Median (IQR) }\end{array}$ & $\begin{array}{c}\text { Friedman's } \\
\text { test } \\
p \text {-value }\end{array}$ \\
\hline Temperature (o) & $38(37.6-38.5)$ & $38.2(37.7-38.3)$ & $37.7(37.3-37.9)$ & $37.3(37.2-37.5)$ & $<0.05$ \\
\hline HR (beat/min) & $105(98-111)$ & $116(111-123)$ & $110(100-120)$ & $102(96.5-110)$ & $<0.05$ \\
\hline RR (beat/min) & $21(19-23)$ & $22(20-27)$ & $22(19-25.7)$ & $18(15.7-20.5)$ & $<0.05$ \\
\hline PCO2 (mmHg) & $35(33.3-35.6)$ & $34(33-35)$ & $34(31-37.2)$ & $35.2(33.8-42.7)$ & $>0.05$ \\
\hline $\operatorname{TLC}\left(10^{3} / \mu \mathrm{L}\right)$ & $16.2(13.3-22.1)$ & $13.4(10-18.2)$ & $10.9(7.5-15.6)$ & $10.3(6.3-14.3)$ & $<0.05$ \\
\hline SIRS score & $3(1-4)$ & $2(1-4)$ & $1(0-3)$ & $0(0-1)$ & $<0.05$ \\
\hline
\end{tabular}

HR: Heart rate.

RR: Respiratory rate.

TLC: Total leucocytic count.

IQR: Interquartile range.

SIRS: Systemic inflammatory response syndrome.

Table (6): Postoperative outcome data among the studied patients.

\begin{tabular}{ll}
\hline Variables & Frequency $(\%)$ \\
\hline Rejection (\%) & $50(22.5-97.5)$ \\
(LOS) (days) & $21(14-30.7)$ \\
Wound infection & $10(32.3 \%)$ \\
Mortality rate & $4(12.9 \%)$ \\
Final decision: & \\
$\quad$ Conservative therapy & $22(81.5 \%)$ \\
$\quad$ A small area of autograft & $5(18.5 \%)$ \\
\hline
\end{tabular}




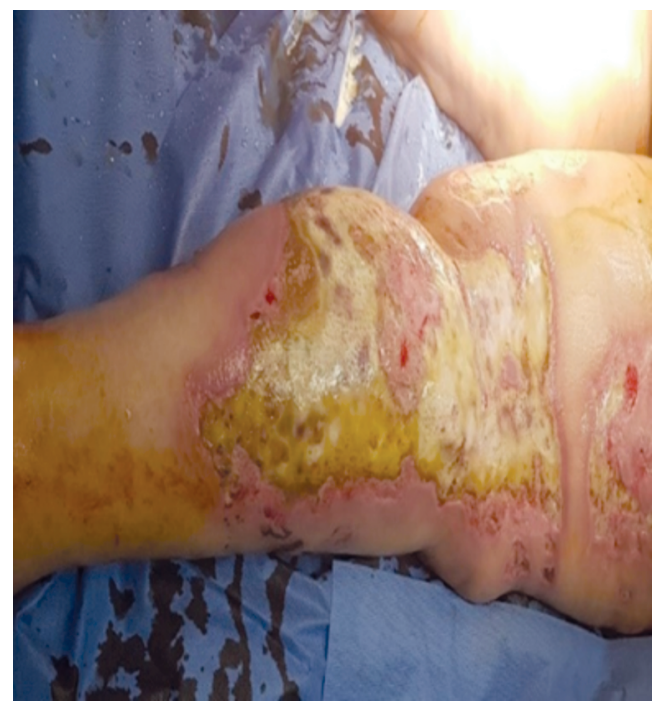

Fig. (1): Intraoperative burn wound before Escharectomy and debridement.

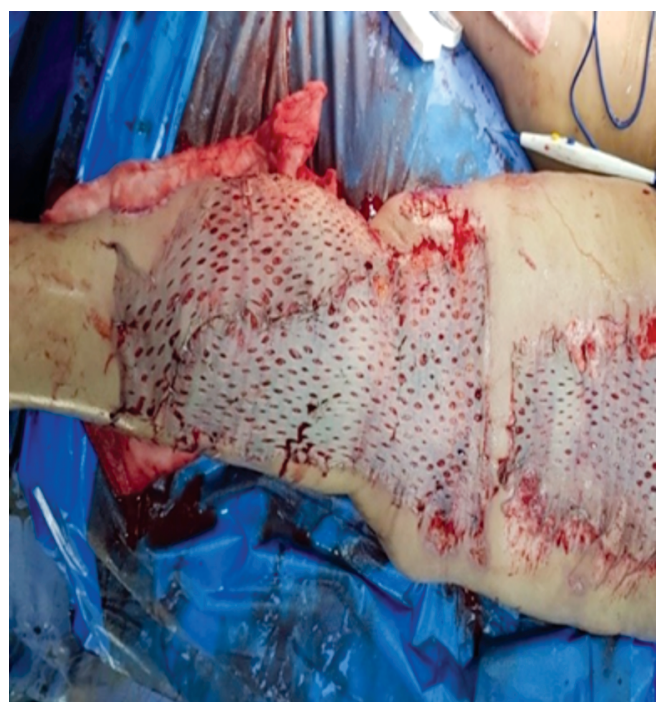

Fig. (2): Homograft applied and fixed in place.
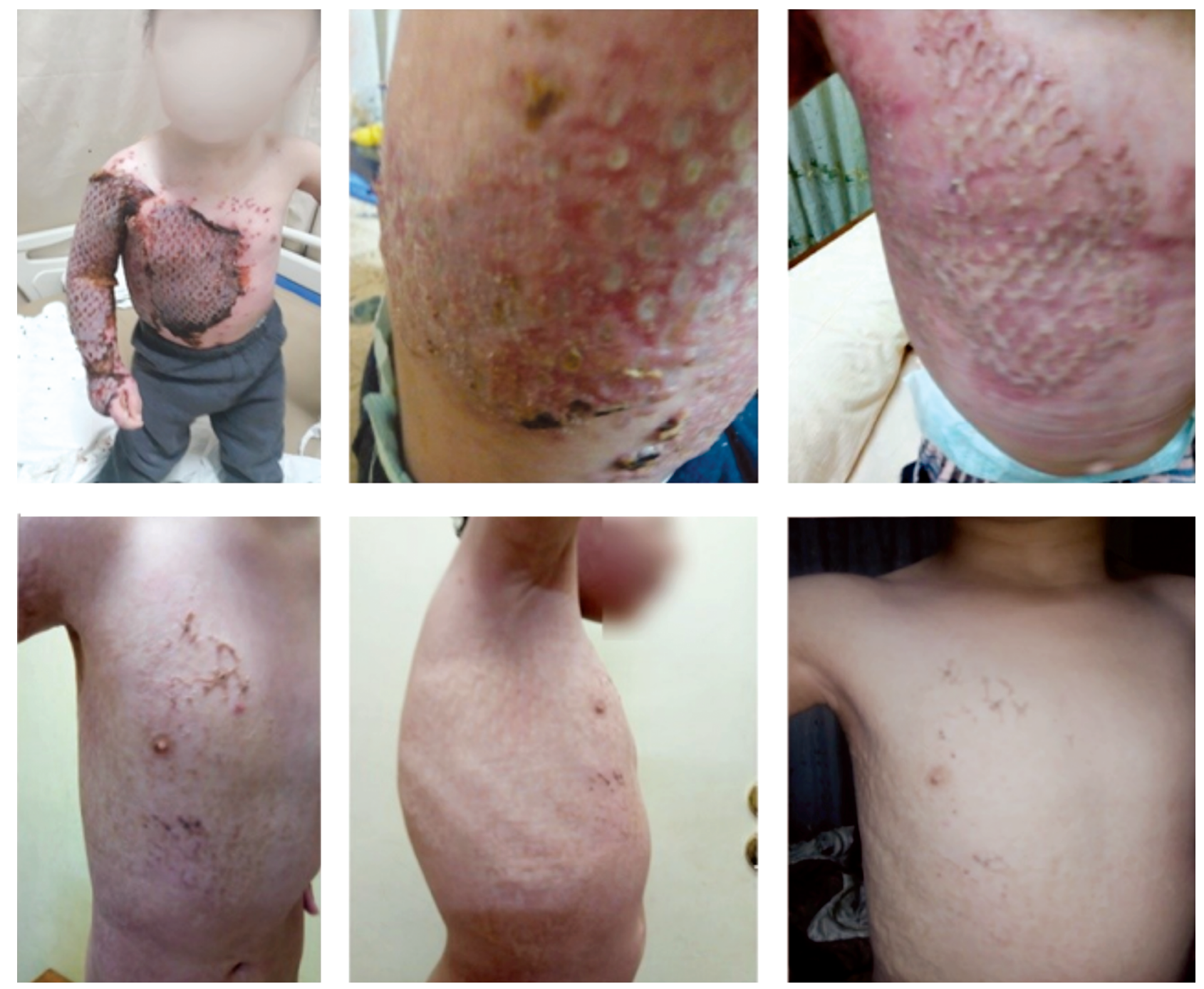

Fig. (3): Complete take of the homograft in a 2 years-old child after long term follow-up for one and half year. 


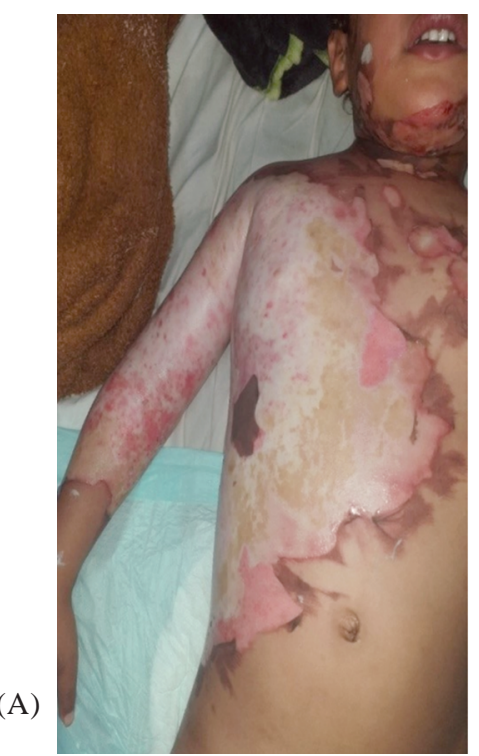

(B)
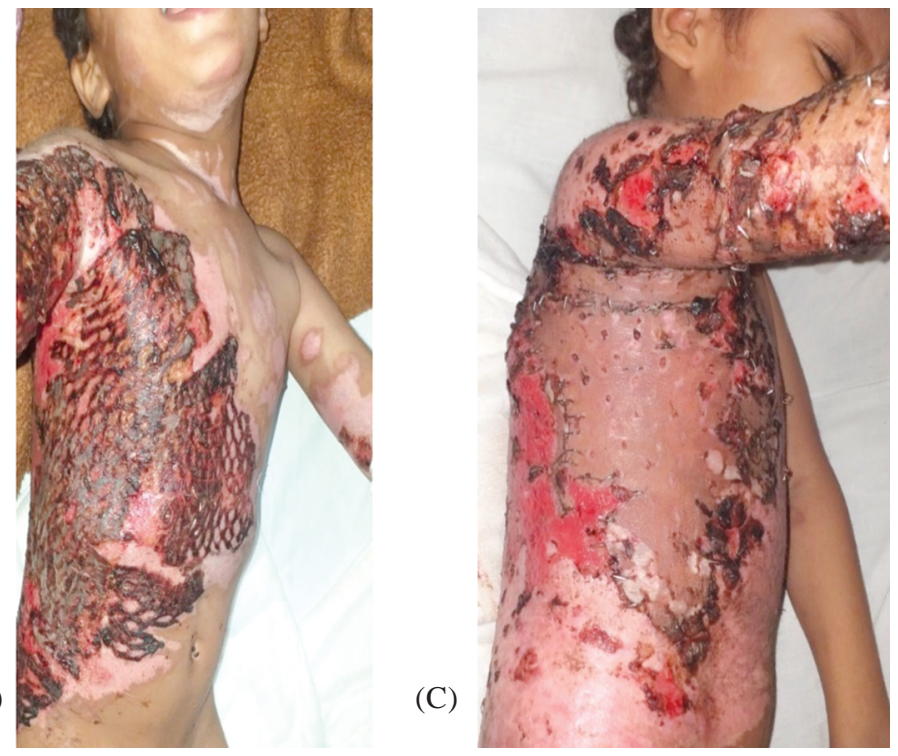

Fig. (4): Pre and post homograft application in a 4-year-old male.

(A): Pre-operative. (B): Early post-operative. (C): Late post-operative with the start of rejection and signs of healing.
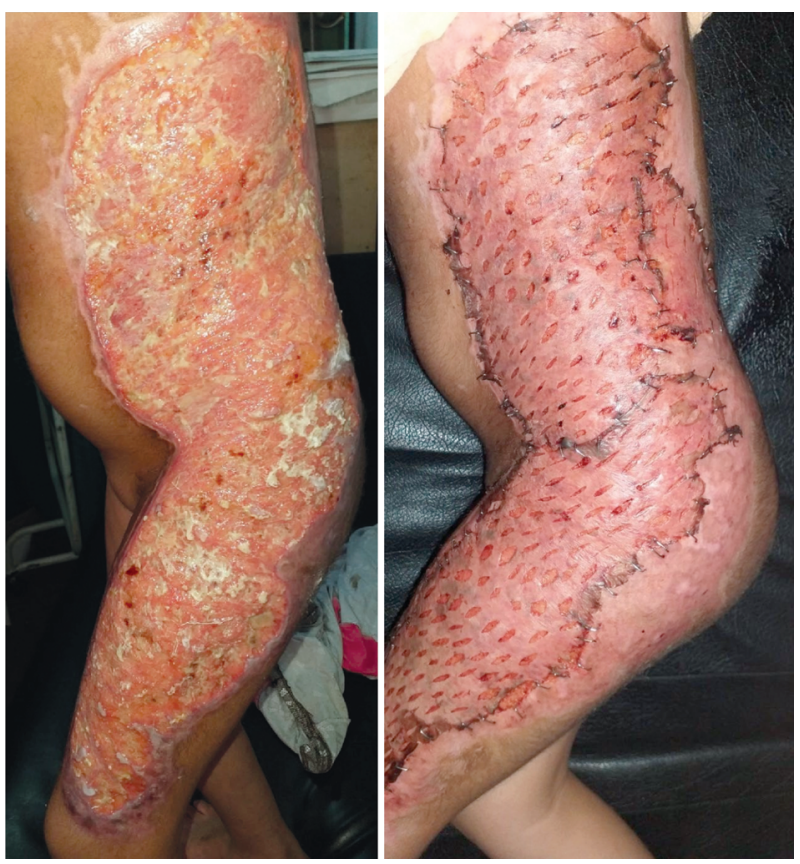

Fig. (5): Pre and post homograft application in a 6-year-old female.

\section{DISCUSSION}

One of the most common types of injury all around the world is burn. Every year, more than 11 million people require medical treatment for burns [12]. Since healthy skin is essential for preserving the human body's physiological homeostasis, the aim in the treatment of burn is to turn an open wound into a closed one [13].

This study is conducted to evaluate the use of fresh skin homograft in major burn patients by comparing the laboratory results pre-and postoperative and documenting the changes of the results before and after using homograft. We also tried to document the incidence of SIRS occurrence as a predictor of sepsis and detect the effect of homograft in preventing sepsis, which is a consequence of major burn.

Considering basic clinical data, the mean age of all patients was (11.876) years, which was consistent with Abdelwahab et al., research which was done on 82 burn patients at Tanta University in Egypt from 2016 to 2017. The mean age of their study was (16.5) [14]. The age of patients enrolled in the current study was a little younger because finding a skin donor for a kid, from the parents in most cases, is easier than for an adult. This contrasts with Troy et al., study, which was done in Florida, USA, on 157 burn victims. Their study's mean age was (37.3). They discovered that the majority of burn victims in developing countries are children. This could be attributed to a lack of safety precautions or a lack of awareness [15].

Regarding the gender of the patients, $(54.8 \%)$ of patients were males, while $(45.8 \%)$ were females, with $(3.2 \%)$ of patients were smokers and had DM and $\mathrm{HCV}$, respectively, which came in agreement with Hardwicke et al. and El-Meanawy et al. [16,17].

In this study, first-degree relatives or second degree on some occasions were the sources of the fresh skin homograft. We believe that this method has many advantages, which agrees with what Phipps and Clarke [18] and Coruh et al. [19] said 
in their studies. They feel some specific advantages derive from using skin from a parent rather than an unrelated donor, such as:

1- The allograft skin is freshly donated, avoiding the need for storage facilities or complex treatment and packaging, and presenting the skin at maximum viability.

2- There is a considerable psychological benefit to the donor parent, who feels that he is making a significant contribution to his child's recovery.

3- The transmission of diseases as HIV is unlikely after a frank discussion of this potential problem with the family [18].

4- Close HLA matching also may allow the prolongation of allograft survival [19].

Megahed et al., in their study, showed the same as the current study results regarding WBCs. A significant decrease in WBCs level after homograft application has been reported [20]. Do that ensure the importance of homograft in control of SIRS in those patients. Regarding the current study, there was a significant decrease in temperature postoperative, which disagrees with Troy et al., they reported non-significant improvement in temperature, and $3 \%$ of their cases suffered from high temperature due to cellulitis. The usage of relative's skin allograft in our study could explain this difference, but in Troy et al., study, they use EZ derm ${ }^{\circledR}$, which is Porcine derived skin substitute [15].

This study showed a significant improvement in electrolyte imbalance after homograft. The results showed a significant increase in sodium level post-operative, which can be explained by decreasing fluid loss by early wound coverage using homograft, coincident with the fluid resuscitation regimen. Adly et al., in their study, used amniotic membrane as a biological coverage and polyurethane membrane as a synthetic one. Their results showed no electrolyte disturbance in most patients at the biological coverage group, which comes in agreement with the current study, while there was a disturbance in the electrolyte at the synthetic membrane group. This denotes the efficacy of the biological coverage over the synthetic one in controlling electrolyte loss [21].

It worth mentioning that there was an improvement in both hemoglobin and platelet levels preand post-operative. This non-significant improvement is most probably due to the consideration of blood transfusion peri-operative whenever needed. This comes in agreement with Agarwal et al., study, as they notice an improvement of hemoglobin level from $11.02 \mathrm{~g} / \mathrm{dL}$ preoperative to $11.5 \mathrm{~g} / \mathrm{dL}$ postoperative day 10 (POD10) [22].

Regarding post-operative outcome data, the median rejection \% was (50\%). El-Meanawy et al., reported in their study that the percentage of graft rejection among the homograft only group was (54.28) which agreed with the current study results, while the other group of combined homograft and autograft, the graft rejection percentage was (31.088), that is lower than our results, but indicate that combining the autograft with the homograft could decrease the rejection percentage [17].

Five cases $(18.5 \%)$ in the current study need a small area of autograft after homograft application due to a small raw area that has been lifted and needed coverage. This comes in agreement with Adly et al., study, as the percentage of raw area in his study was that needs skin graft was $(17.4 \%)$. That indicates that the dermal pad formed even after the biological graft rejection could help wound healing alone without the need for grafting [21].

The mortality rate was (12.9\%), which came in agreement with El-Meanawy et al. [17]. This mortality rate $(12.9 \%)$ is less than El Mehrat et al., which calculated for the period 2006-2010 and was $(18.6 \%)$ in the same unit, and less than a previous study conducted in the same unit during the period 2002-2004 and was $24.1 \%$, to which indicates an improvement in the treatment protocol and inpatient care [23].

Despite homograft from identical twins has much more chance on the complete take as reported for examples in Converse \& Duchet study [24]. However, two years later, Kearns \& Ried had another study carried on a nine-year-old child, they used skin from their parents, exactly as the two cases of our current study, and the taken was successful. They could not explain the exact cause of complete taken in such time [25]. The exact causes of acceptance or rejection only referred to theories as HLA (human leukocyte antigen) compatibility causes or the low immunity of the kids with the major burn at the time of homograft application [26]. However, this could open the field for more homograft applications later.

\section{Limitation of the study:}

1 - The presence or absence of the control group was one of the problems that faced the current study. The control group options were either: (1) Patients who not treated by any means of coverage. But they did not exist at the study time as we were 
trying to save those patients alive by measures of burn wound coverage as much as we can. (2) Patients were treated with autograft. But most patients have a paucity of normal skin after the affection of most of their skin by burning. And the control group in such case will be composed of patients with lower burn surface area than the current study. (3) Patients were treated with other skin substitutes. But due to low income and low funding for such patients coincident with the high cost of the synthetic skin substitutes, make this option not available. The other options were making a retrospectively controlled group or a control group from other local hospitals. But we faced other problems, as factors other than homograft will come out on the surface, such as different treatment protocols, fluid management criteria, and different workplaces. All these factors could mask the results.

2- Limited sample number and lack of followup in many cases.

\section{Conclusion:}

The current work concluded that the use of homograft in major burn patients improved their overall condition by improving laboratory and respiratory data post-operatively. Furthermore, reducing the raw area which consequently reduces the fluid and electrolyte loss, besides aiding in rapid wound healing. Furthermore, we discovered a significant reduction in the SIRS score, which reduces sepsis and improves morbidity and mortality.

\section{REFERENCES}

1- World Health Organization: Management of Burns; WHO/EHT/CPR. Link on the internet: https:// www.who.int/surgery/publications/Burns_management. pdf, 2007.

2- Kramer L.: Third Degree Burns and Dehydration. Burn Injury Resource Center. Website link on the internet :https://www.burn-injury-resourcecenter.com/ thirddegreeburns-and-dehydra/, 2011.

3- Stanton R.A. and Billmire D.A.: Skin resurfacing for the burned patient. Clinics in Plastic Surgery, 29 (1): 29-51, 2002.

4- Shores J.T., Gabriel A. and Gupta S.: Skin substitutes and alternatives: A review. Advances in Skin \& Wound Care, 20 (9): 493-508, 2007.

5- Balk R.A.: Systemic inflammatory response syndrome (SIRS) Where did it come from and is it still relevant today? Virulence, 5 (1): 20-26, 2014.

6- Rowan M.P., Cancio L.C., Elster E.A., Burmeister D.M., Rose L.F., et al.: Burn wound healing and treatment: Review and advancements. Critical Care, 19 (1): 243, 2015.
7- Shevchenko R.V., James S.L. and James S.E.: A review of tissue-engineered skin bioconstructs available for skin reconstruction. Journal of the Royal Society Interface, 7 (43): 229-258, 2010.

8- Hermans M.H.: Preservation methods of allografts and their lack of influence on clinical results in partialthickness burns. Burns, 37 (5): 873-881, 2011.

9- Bravo D., Rigley T.H., Gibran N., Strong D.M. and Newman-Gage H.: Effect of storage and preservation methods on viability in transplantable human skin allografts. Burns, 26 (4): 367-378, 2000.

10- Yussof M.S.J., Halim A.S., Saad M.A.Z. and Jaafar H.: Evaluation of the Biocompatibility of a Bilayer Chitosan Skin Regenerating Template, Human Skin Allograft, and Integra Implants in Rats. ISRN Materials Science, 2011: 2011.

11- Goodyear M.D., Eckenwiler L.A. and Ells C.: Fresh thinking about the Declaration of Helsinki. British Medical Journal Publishing Group, 337: a2128, 2008.

12- Varkey M., Visscher D.O., van Zuijlen P.P., Atala A. and Yoo J.J. Skin bioprinting: The future of burn wound reconstruction? Burns \& Trauma, 7: s41038-019, 2019.

13- Sorg H., Tilkorn D.J., Hager S., Hauser J. and Mirastschijski U.: Skin wound healing: An update on the current knowledge and concepts. European Surgical Research, 58 (1-2): 81-94, 2017.

14- AbdelWahab M.E., Sadaka M.S., Elbana E.A. and Hendy A.A.: Evaluation of prognostic factors affecting length of stay in hospital and mortality rates in acute burn patients. Annals of burns and fire disasters, 31 (2): 8388, 2018.

15- Troy J., Karlnoski R., Downes K., Brown K.S., Cruse C.W., et al.: The use of EZ Derm ${ }^{\circledR}$ in partial-thickness burns: An institutional review of 157 patients. Eplasty, 13, 2013.

16- Hardwicke J., Kohlhardt A. and Moiemen N.: The Birmingham Burn Centre archive: A photographic history of post-war burn care in the United Kingdom. Burns, 41 (4): 680-688, 2015.

17- El-Meanawy A.M., Keshk T.F., Lolouah M.A. and Hassan M.S.: The reliability of use of combined homograft and autograft in management of major burns. International Surgery Journal, 6 (5): 1436-1442, 2019.

18- Phipps A.R. and Clarke J.A.: The use of intermingled autograft and parental allograft skin in the treatment of major burns in children. British Journal of Plastic Surgery, 4(8): 608-611, 1991.

19- Coruh A., Tosun Z. and Ozbebit U.: Close Relative Intermingled Skin Allograft and Autograft Use in the Treatment of Major Burns in Adults and Children. Journal of Burn Care \& Rehabilitation, 26 (6): 471-477, 2005.

20- Megahed M.A., El Kashty S.M., Nassar A.T. and Ghazal M.I.: Biochemical and immunological changes as prognostic factors after homografts application for the management of major burn patients. Menoufia Medical Journal, 33 (2): 688-693, 2020.

21- Adly O.A., Moghazy A.M., Abbas A.H., Ellabban A.M., Ali O.S., et al.: Assessment of amniotic and polyurethane membrane dressings in the treatment of burns. Burns, 36 (5): 703-710, 2010. 
22- Agarwal P., Prajapati B. and Sharma D.: Evaluation of skin graft take following postburn raw area in normovolaemic anemia. Indian journal of plastic surgery: Official publication of the Association of Plastic Surgeons of India, 42 (2): 195, 2009.

23- El Mehrat A.M., Ghareeb F.M., Keshk T.F., El Sheikh Y.M. and Ibrahim A.H.: Retrospective study of mortality and causes of death in Menofia University Burn Center. Menoufia Medical Journal, 27 (2): 290, 2014.

24- Converse J.M. and Duchet G.: Successful homologous skin grafting in a war burn using an identical twin as donor. Plastic and Reconstructive Surgery, 2 (4): 342344, 1947.

25- Kearns J.E. and Reid S.E.: Successful Homotransplantation of Skin from Parents to Son. Plastic and Reconstructive Surgery, 4 (6): 502-507, 1949.

26- Higuchi D., Sei Y. and Takiuchi I.: Influence of histocompatibility antigens on skin homograft survival in an extensively burned patient. The Journal of Dermatology, 8 (1): 47-52, 1981. 